\title{
INCLEN - BMGF Research Program to Emphasize Context Sensitive Approaches for Addressing the Challenges of Childhood Pneumonia in India
}

\author{
Manoja Kumar Das, Narendra Kumar Arora* \\ The INCLEN Trust International, New Delhi. \\ "nkarora@inclentrust.org
}

A cute respiratory infection (ARI) and pneumonia scenario in children have changed enormously in the last 20 years; there is global reductions in aetiology due to introduction of effective vaccines and improvements in case detection and management. Notwithstanding these gains, huge variation in pneumonia morbidity and mortality emerge between, and within, different countries. In 2015, India was the top contributor to pneumonia disease burden globally (32\%) [1]. During the Millennium Development Goal era (2000-2015), India contributed to the highest to the clinical pneumonia burden globally (32\%) and observed only 3\% decline in the number of pneumonia episodes [1,2]. Noticeable socio-cultural and economic changes have occurred in India since the 90s: lifestyle changes, urbanisation, migration, and, aspiration for better living conditions. Vaccines for $H$. influenza and Pneumococcus have been introduced in addition to expanding coverage for measles as part of the Measles Rubella Elimination campaign. These contrasting observations emphasize importance of context-sensitive control strategies and focus for equity if the country desires to witness decline in the pneumonia burden and related deaths.

To support and accelerate India's efforts towards reducing pneumonia deaths and emphasize its public health significance, a research program was supported by Bill and Melinda Gates Foundation (BMGF) through the INCLEN Trust International. This research program aimed to provide catalytic support to the Indian investigators and institutions for generation of context specific evidence and knowledge on childhood pneumonia that has policy and program relevance. This childhood pneumonia research program in India was coordinated and managed by INCLEN under guidance of a Joint Working Group (JWG) with membership (14 members) from Ministry of Health and Family Welfare, Department of Biotechnology, Indian Council of Medical Research, and Government of India, World Health Organisation (WHO), Unicef and technical experts of national and international repute. Seven focus areas for funding were finalized: $(i)$ determinants of pneumonia burden and deaths; (ii) improving case management with better access that mitigates barriers to care seeking; (iii) aetiology, determinants and outcome of neonatal pneumonia; $(i v)$ diagnostic tools and point of care diagnosis; (v) respiratory syncytial virus pneumonia, particularly in neonatal and early infancy; (vi) pneumococcal conjugate vaccine scheduling and immunogenicity; and (vii) epidemiological tools for monitoring and surveillance of pneumonia and ARI program and impact assessment of different interventions. Overarching expectation from these studies has been of understanding subnational variation and contextual factors.

Amultidisciplinary Technical Advisory Group (TAG) (n32) including national and international experts from child health, pneumonia, microbiology, public health, social science, biostatistics, health economics, and health program reviewed 94 concept notes, down selected 29 applicants for full proposal submission and finally, approved ten proposals for funding. The selected proposals were not only from established researchers from leading institutions, but also included innovative ideas from four young and lessexperienced investigators. Hand-holding and mentoring framework was embedded in to program governance particularly for young and new investigators. The TAG members designated for specific projects provided technical mentoring through progress review and site visits. The investigators were provided opportunity to attend Research LAMP (Leadership and Management Program) conducted regularly by INCLEN; one research methodology workshop was also organised for the young investigators and research team members. The young investigators were also supported for data management, analysis and manuscript writing.

The ten supported studies focused on care-seeking behavior and determinants, case diagnosis and management, impact of alternate vaccine schedule, and cost effectiveness and etiology of neonatal pneumonia. It is interesting that the research projects supported under this program overlapped with seven priority research domains 
identified in a recent ARI and pneumonia review commissioned by maternal, neonatal, child and adolescent health (MNCAH) division of WHO for exploring contextual challenges to decrease ARI related morbidities and mortality [3].

From these ten supported projects under this pneumonia research program, 29 manuscripts were submitted. While 14 articles have been already published in other international and national peer reviewed indexed journals [4-17], six research articles and one systematic review are included in this issue. Eight additional articles are under review. Two investigators have strengthened the research infrastructure at their institutions, and seven investigators have generated new research proposals catalysed by this program.

An external evaluation of the program was conducted by a three-member team to assess the public health appropriateness, program implementation and contribution to the research pool in Indian context [18].

The BMGF-INCLEN program was conceived in alignment with the mission and vision of The INCLEN Trust International. We expect this model of targeted research investment attempting to answer local challenges along with proactive efforts to expand the pool of young researchers will stimulate similar programs in future as well.

Funding: This project was supported by the Bill and Melinda Gates Foundation, USA to The INCLEN Trust International (grant number OPP1084307). The funder or its representative had no role in the design of the study and collection, analysis, and interpretation of data and writing the manuscript.

Competing interest: None stated.

\section{REFERENCES}

1. McAllister DA, Liu L, Shi T, et al. Global, regional, and national estimates of pneumonia morbidity and mortality in children younger than 5 years between 2000 and 2015: a systematic analysis. Lancet Glob Health. 2019;7(1):e47-57.

2. Million Death Study Collaborators, Bassani DG, Kumar R, et al. Causes of neonatal and child mortality in India: a nationally representative mortality survey. Lancet. 2010;376:1853-60.

3. Pneumonia Review Team. Evidence synthesis on Acute Respiratory Infection (ARI) and pneumonia in children Summary report for the World Health Organization's (WHO) Department of Maternal, Newborn, Child and Adolescent Health and Ageing. Melbourne, Australia: Murdoch Children's Research Institute (MCRI), University of Melbourne; 2021.

4. Gothankar J, Doke P, Dhumale G, et al. Reported incidence and risk factors of childhood pneumonia in India: a communitybased cross-sectional study. BMC Public Health. 2018;18(1):1111.

5. Doke PP, Gothankar JS, Dhumale GB, et al. Model package of Behavioral Change Communication regarding childhood pneumonia and its risk factors: a pre-post assessment. Indian J Community Health. 2020;32(1):67-75.
6. Murarkar S, Gothankar J, Doke P, et al. Prevalence of the Acute Respiratory Infections and Associated Factors in the Rural Areas and Urban Slum Areas of Western Maharashtra, India: A Community-Based Cross-Sectional Study. Front Public Health. 2021;9:723807.

7. Murarkar S, Gothankar J, Doke P, et al. Prevalence and determinants of undernutrition among under-five children residing in urban slums and rural area, Maharashtra, India: a community-based cross-sectional study. BMC Public Health. 2020;20(1):1559.

8. Mohanraj R, Kumar S, Jayakumar S, et al. Where do mothers take their children for pneumonia care? Findings from three Indian states. Gopichandran V, editor. PLOS One. 2019;14(4):e0214331.

9. Nair NS, Lewis LE, Lakiang T, Godinho M, Murthy S, Venkatesh BT. Factors associated with mortality due to neonatal pneumonia in India: a protocol for systematic review and planned meta-analysis. BMJ Open. 2017;7(9):e017616.

10. Nair S, Lewis LE, Godinho MA, Murthy S, Lakiang T, Venkatesh BT. Factors associated with neonatal pneumonia in India: protocol for a systematic review and planned metaanalysis. BMJ Open. 2018;8(1):e018790.

11. Nair NS, Lewis LE, Lakiang T, Godinho MA, Murthy S, Venkatesh BT. Risk factors and barriers to case management of neonatal pneumonia: protocol for a pan-India qualitative study of stakeholder perceptions. BMJ Open. 2017;7(9):e017403.

12. Nair NS, Lewis LE, Murthy S, Godinho MA, Lakiang T, Venkatesh BT. Treatment options and barriers to case management of neonatal pneumonia in India: a protocol for a scoping review. BMJ Open. 2017;7(9):e017617.

13. Godinho MA, Murthy S, Lakiang T, Puranik A, Nair SN. Mapping Neonatal Mortality in India: A Closer Look. Indian J Community Med Off Publ Indian Assoc Prev Soc Med. 2017;42(4):234-7.

14. Murthy S, Godinho MA, Guddattu V, Lewis LES, Nair NS. Risk factors of neonatal sepsis in India: A systematic review and meta-analysis. Cheungpasitporn W, editor. PLOS ONE. 2019 Apr 25;14(4):e0215683.

15. Awasthi S, Verma T, Agarwal M, Pandey CM. To assess the effectiveness of various communication strategies for improving childhood pneumonia case management: study protocol of a community based behavioral open labeled trial in rural Lucknow, Uttar Pradesh, India. BMC Pediatr. 2018 Dec;18(1):279.

16. Awasthi S, Kumar D, Mishra N, Agarwal M, Pandey CM. Effectiveness of various communication strategies for improving childhood pneumonia case management: a community based behavioral open labeled trial in rural Lucknow, Uttar Pradesh, India. BMC Public Health. 2019 Dec;19(1):1721.

17. Farooqui HH, Jit M. The potential impact and costeffectiveness of current and future pneumococcal conjugate vaccines in India. Int J Infect Dis. 2019 Feb;79:134-5.

18. Cherian T, Gupta P, Thomas K. An External Evaluation on the INCLEN Research Program to Emphasize the Public Health Significance of Childhood Pneumonia in India. Indian Pediatr. 2021;58:1074-6. 